\title{
Microbiological Profile of Adenoid Hypertrophy Correlates to Clinical Diagnosis in Children
}

\author{
Anita Szalmás, ${ }^{1}$ Zoltán Papp, ${ }^{2}$ Péter Csomor, ${ }^{2}$ József Kónya, ${ }^{1}$ István Sziklai, ${ }^{2}$ \\ Zoltán Szekanecz, ${ }^{3}$ and Tamás Karosi ${ }^{2}$ \\ ${ }^{1}$ Department of Medical Microbiology, Medical and Health Science Center, University of Debrecen, Nagyerdei Krt. 98, \\ Debrecen 4032, Hungary \\ ${ }^{2}$ Department of Otolaryngology and Head and Neck Surgery, Medical and Health Science Center, University of Debrecen, \\ Nagyerdei Krt. 98, Debrecen 4032, Hungary \\ ${ }^{3}$ Department of Rheumatology, Medical and Health Science Center, University of Debrecen, Nagyerdei Krt. 98 , \\ Debrecen 4032, Hungary
}

Correspondence should be addressed to Tamás Karosi; karositamas@gmail.com

Received 24 April 2013; Accepted 23 August 2013

Academic Editor: Ralph Mösges

Copyright @ 2013 Anita Szalmás et al. This is an open access article distributed under the Creative Commons Attribution License, which permits unrestricted use, distribution, and reproduction in any medium, provided the original work is properly cited.

\begin{abstract}
Objective. Adenoid hypertrophy is a common condition in childhood, which may be associated with recurring acute otitis media (RAOM), otitis media with effusion (OME), and obstructive sleep apnea syndrome (OSAS). These different clinical characteristics have some clinical overlap; however, they might be explained by distinct immunologic and infectious profiles and result in various histopathologic findings of adenoid specimens. Methods. A total of 59 children with adenoid hypertrophy undergoing adenoidectomy were studied. Three series of identical adenoid specimens were processed to hematoxylin-eosin (H.E.) and Gram staining and to respiratory virus specific real-time PCR, respectively. Results. According to the clinical characteristics, patients were recruited into three groups: RAOM $(n=25)$, OME $(n=19)$, and OSAS $(n=15)$. Bacterial biofilms were detected in 21 cases, while at least one of the studied respiratory viruses was detected in 52 specimens. RAOM cases were significantly associated with biofilm existence $(n=20, P<0.001)$. In contrast, OME group was characterized by the absence of bacterial biofilm and by normal mucosa. Showing a statistically significant correlation, all OME cases were positive for human bocavirus (HBoV, $P<0.001)$. Conclusions. Bacterial biofilms might contribute to the damage of respiratory epithelium and recurring acute infections resulting in RAOM. In $\mathrm{OME}$ cases persisting respiratory viruses, mainly $\mathrm{HBoV}$, can cause subsequent lymphoid hyperplasia leading to ventilation disorders and impaired immunoreactivity of the middle ear cleft.
\end{abstract}

\section{Introduction}

Adenoid hypertrophy (adenoid vegetation) and associated symptoms of children are a common condition in pediatrics and ENT practice that is responsible for a great amount of medical visits and one of the main reasons for antibiotic treatment and parental leave of work [1]. Nasopharyngeal obstruction caused by adenoid hypertrophy may lead to several other diseases and symptoms such as hyponasality, snoring, obstructive sleep apnea syndrome (OSAS), acute otitis media, otitis media with effusion (OME), middle ear atelectasia, cholesteatoma formation, slow feeding, acute sinusitis, abnormal facial development, and behavioral problems [25]. Adenoidectomy with or without tympanocentesis or ventilation tube insertion is a useful surgical intervention to treat hearing problems, obstructive sleep apnea syndrome, and to prevent recurring otitis media, recurring sinusitis, and cholesteatoma formation or middle ear atelectasia [6-8]. In Hungary (population is 10 million), 6-9,000 adenoidectomies have been performed annually in the latest years emphasizing the extent of this condition. The annual number of reported adenoidectomies varies between 15,000 and 50,000 in the United States and between 50,000 and 70,000 in the European Union $[7,8]$. In the clinical practice, symptoms and conditions associated with adenoid hypertrophy can be classified into distinct clinical groups as follows: (1) recurring acute otitis media (RAOM), (2) otitis media with effusion (OME), 
and (3) obstructive sleep apnea syndrome (OSAS) [9-13]. In contrast to potential clinical overlaps, clinical behavior, recurrence rates, and therapeutic responses are absolutely different in these groups $[1,11,12,14]$. Hypertrophic adenoid (epipharyngeal tonsil) may directly obstruct the ostia of Eustachian tubes predisposing children to $\operatorname{OME}[1,2,10]$. However, this mechanical hypothesis is not widely accepted $[15,16]$. Recurring and chronic infections of the adenoids without manifesting nasopharyngeal obstruction may also lead to the aforementioned conditions by tubal edema and functional disorders supporting the reservoir theory $[1,9,17]$.

Diagnosis of adenoid hypertrophy associated with OME is based on the duration of conductive hearing disorder, typeB tympanograms, and positive otoscopic findings, which persists over 12 weeks despite medical treatment $[10,11]$. OME is a separate diagnostic entity, although the etiopathogenesis is still unclarified $[3,9,15,16]$. Several hypotheses have been arisen in the explanation of the pathogenesis of OME, which is currently thought to be an immunologic disease affected by multiple factors $[10,15,16]$. These are persisting respiratory viral infections, immunological dyscrasias, alimentary allergies, allergic rhinitis, bronchial asthma, and Eustachian tube functional disorders $[3,14,15,18]$. There is increasing evidence that persisting respiratory viruses and impaired immunoreactions may play a promoting role in the pathogenesis of OME associated with adenoid hypertrophy [18-20].

OSAS in childhood is a complex clinical condition that can be affected by several anatomic and pathologic disorders, as well as adenoid hypertrophy, tonsillar hypertrophy, nasal obstruction, laryngeal malformations, macroglossia, maxillofacial malformations, and so forth $[12,13]$. As to our current knowledge, pure OSAS cases associated to simple adenoid hypertrophy have not been attributed to immunologic or infectious disorders $[12,13]$.

RAOM is also a separate clinical entity, which might be associated to the presence of bacterial biofilms on the surface of epipharyngeal mucosa $[17,21,22]$. Biofilm creates a special environment for microbial survival and proliferation that consists of a self-produced, three-dimensional extracellular matrix formed by polysaccharides, proteins, nucleic acids, and water [21, 23, 24]. Microbial biofilms are characterized by extremely high resistance against antibiotics, host immune reactions, and chemical and physical agents [21, 22]. This strong and continuously remodeled physical barrier blocks the diffusion of antibiotics, superoxides, immunoglobulins, and opsonins [21,25]. Biofilms and consecutive inflammatory reactions might contribute to the epithelial damage and subsequent hyperplasia of the subepithelial layer resulting in adenoid hypertrophy $[1,9,23,24]$. It has been reported that persisting biofilms in adenoid hypertrophy may be responsible for surgical failures and high recurrence rate of acute suppurative otitis media $[3,8,10,15]$.

This study investigates the presence of bacterial biofilms and respiratory viruses in adenoid specimens obtained from patients with adenoid hypertrophy and associated conditions. Histopathologic findings and respiratory virus specific realtime PCR results were correlated to the clinical characteristics of prospectively formed patient groups.

\section{Materials and Methods}

2.1. Patients. A prospective case-control experimental study was performed on adenoid specimens obtained from children with adenoid hypertrophy who underwent adenoidectomy at the Department of Otorhinolaryngology and Head and Neck Surgery, University of Debrecen. Adenoid samples $(n=59)$ were collected between January and May 2012. The patient group consisted of 37 males and 22 females $(n=59$, mean age $=5.09$ years; range $=3-11$ years) with the diagnosis of adenoid hypertrophy and associated symptoms such as otitis media with effusion, recurring acute otitis media, and obstructive sleep apnea syndrome. Clinical diagnosis was confirmed by preoperative evaluation of patients' history obtaining heteroanamnesis from parents and by physical and audiologic examinations. During the prospective data collection, patients were recruited into three clinical categories forming distinct groups of (1) recurring acute otitis media (RAOM), (2) otitis media with effusion (OME), and (3) obstructive sleep apnea syndrome (OSAS), respectively. Inclusion criteria were based on the rate of episodes of acute suppurative otitis media, acute sinusitis or sinobronchitis, on the otoscopic findings, audiologic examinations (pure tone threshold audiometry and tympanometry), and finally on patients' history. All surgical interventions were performed under intratracheal narcosis. All the adenoid samples collected during adenoidectomy were divided into two consecutive groups consisting of 59 specimens each that were processed to histopathologic analysis and respiratory virus specific real-time PCR, respectively. All adenoid specimens were larger than 2 centimeters of diameter, which could be removed by a sharp adenotom device without any surface injury or iatrogenic disruption of biofilm layers. The transoral removal was gently performed at the basis of adenoids avoiding the surgical injury of torus tubarius, nasal septum, and the mesopharyngeal mucosa. In several cases, adenoidectomy was combined by tympanocentesis and suction of the middle ear fluid content. Middle ear fluids were visually analyzed and categorized into serous or mucous groups. All surgeries were performed by two ENT specialists having more than 10 years of experience (Z. Papp and T. Karosi). All parents gave their informed consent before donating the tissue samples for the study. The Institutional Ethical Committee approved our study. The study was carried out according to the Declaration of Helsinki.

2.2. Histopathologic Examination. According to previous reports, combination of H.E. and Gram staining protocols seems to be a usable method for the detection of biofilm existence and corresponding histopathologic changes, since H.E. staining is for the investigation of microscopic architecture, while Gram protocol stains various bacterial elements [25]. The first series of adenoid specimens $(n=59)$ were fixed in $10 \%(\mathrm{w} / \mathrm{v})$ formaldehyde. Specimens were embedded in $15 \%$ $(\mathrm{w} / \mathrm{v})$ purified gelatin $\left(24 \mathrm{~h}, 56^{\circ} \mathrm{C}\right)$ and refixed in $4 \%(\mathrm{w} / \mathrm{v})$ paraformaldehyde $\left(24 \mathrm{~h}, 20^{\circ} \mathrm{C}\right)$. Blocks were cryoprotected in $20 \%(\mathrm{w} / \mathrm{v})$ sucrose-solution $\left(2 \mathrm{~h}, 4^{\circ} \mathrm{C}\right)$ and sectioned into $5 \mu \mathrm{m}$ slides at $-25^{\circ} \mathrm{C}$ (MNT-200, Slee, Mainz, Germany). Slides were stored in $0.1 \mathrm{M}$ PBS containing $0.03 \%(\mathrm{w} / \mathrm{v})$ 
sodium-azide at $4^{\circ} \mathrm{C}$. Two consecutive $5 \mu \mathrm{m}$ frozen cut sections were examined using conventional staining with hematoxylin and eosin (H.E.) and conventional Gram staining, respectively. The criteria for the histopathologic detection of microbial biofilms were the presence of characteristic morphology and Gram positivity/negativity and microcolonies of bacteria and the presence of the surrounding polysaccharide layer upon examination by optical microscopy [25]. Structure and cellular infiltration of the epithelial and also the subepithelial layers were correlated to the presence of bacterial biofilms. Histologic pretreatment protocols were performed by an independent laboratory assistant in all cases. Both sets of histologic staining protocols were independently analyzed by two researchers (P. Csomor and T. Karosi) blinded to clinical diagnosis.

\subsection{Nucleic Acid Extraction and Real-Time PCR Detection} of Respiratory Viruses. Second series of adenoid specimens $(n=59)$ were processed for nucleic acid extraction and purification, which was performed by High Pure Viral Nucleic Acid Kit (Roche Applied Science, Basel, Switzerland) according to the manufacturer's instructions. Simultaneous detection of respiratory viruses with potential pathogenic role was performed by validated and commercial RT (reverse transcriptase) and real-time PCR systems. The following respiratory viruses were tested: influenza virus $A$ and $B$ (Iv$\mathrm{A}$ and $\mathrm{B}$ ); respiratory syncytial virus $\mathrm{A}$ and $\mathrm{B}$ (RSV-A and $\mathrm{B}$ ), human metapneumovirus $\mathrm{A}$ and $\mathrm{B}$ (hMPV-A and B); rhino- and enteroviruses (RV/EV); adenoviruses (AdV, 52 serotypes), and human bocavirus (hBoV 1, 2, 3, and 4). All real-time PCR systems were purchased from Argene (influenza A/B r-gene, Ref: 70-040; RSV/hMPV r-gene, Ref: 70-041; RV and EV/Cc r-gene, Ref: 70-042; AdV/hBoV rgene, Ref: 70-043). Amplification reactions were performed following a uniform protocol according to the manufacturer's specifications and instructions and the results were validated with positive, negative, and cellular controls provided within the amplification kits. Real-time PCR products were electrophoretized in $10 \%(\mathrm{w} / \mathrm{v})$ agarose gel in all cases.

2.4. Statistical Analysis. Statistical assessments were performed by Mann-Whitney's $U$ probe with a $95 \%$ confidence interval and by Chi-square test (SPSS 9.0 for Windows).

\section{Results}

3.1. Patient Groups. Altogether fifty-nine patients with adenoid hypertrophy who underwent adenoidectomy were included in this study. The clinical history and findings of physical and audiologic examinations were obtained during the confirmation of the diagnosis of adenoid hypertrophy and associated problems. Clinical pieces of information on bronchial asthma, allergic rhinitis, and covering symptoms were recorded in different patient groups before surgery (Table 1).

3.2. Recurring Acute Otitis Media (RAOM) Group. For this group of patients, the inclusion criteria were based on 2 or more acute suppurative otitis media and acute sinusitis or sinobronchitis episodes in the year before adenoidectomy (Table 1). Patients suffering from otitis media with effusion confirmed by physical examination and tympanometry were excluded from this group. In contrast, associated obstructive sleep apnea syndrome was not an exclusion criterion. This group of patients consisted of sixteen males and nine females ( $n=25$; mean age 5.12 years; range $3-11$ years). The average number of acute suppurative otitis media episodes was 6.72/year (range: 2-14), while the acute sinusitis episodes reached the average annual number of 5.41 (range: 29) (Table 1). One patient had allergic rhinitis that was based on the clinical history, on the physical examination, and on the allergen-specific intracutaneous (Prick) skin test. Preoperative systemic antibiotic treatment (amoxicillin, cefuroxim, azithromycin, or clarithromycin) was performed in all patients due to recurring acute upper airway tract infections.

3.3. Otitis Media with Effusion (OME) Group. In this patient group, the inclusion criteria were based on persisting middle ear fluid content and Eustachian tube functional disorder confirmed by physical examination and tympanometry (Table 1). Symptoms persisted more than six weeks in spite of medical treatment including intranasal steroids and/or systemic antihistamine therapy. Patients with unilateral or bilateral middle ear effusion were also recruited in this group. Obstructive sleep apnea syndrome was not an exclusion criterion. This group of patients consisted of twelve males and seven females $(n=19$; mean age 4.63 years; range $3-8$ years). The average number of acute suppurative otitis media episodes was 1.21/year (range: $0-4$ ), while the acute sinusitis episodes reached the average annual number of 1.31 (range: 0-3) (Table 1). Nine patients had allergic rhinitis and four patients were diagnosed with bronchial asthma. The diagnosis of bronchial asthma was based on the clinical history and on the respiratory functional test. The final diagnosis of bronchial asthma was stated by an experienced pulmonologist in all cases. Systemic antihistamine medication (cetirizine or desloratadine) and topical steroid (mometasone-furoate monohydrate) treatment were performed in all patients.

3.4. Obstructive Sleep Apnea Syndrome (OSAS) Group. In this group of patients, the inclusion criteria were based on the persisting (more than three months) sleep apnea and snoring confirmed by the heteroanamnesis obtained from the parents (Table 1). Patients with several recurring acute suppurative otitis media and acute sinusitis episodes or chronic otitis media with effusion confirmed by physical examination and tympanometry were excluded from this group. This group of patients consisted of nine males and six females $(n=15$; mean age 4.93 years; range $3-11$ years). The average number of acute suppurative otitis media episodes was 0.33 /year (range: $0-1$ ), while the acute sinusitis episodes reached the average annual number of 0.4 (range: $0-1$ ) (Table 1). Four patients had allergic rhinitis and two other patients had bronchial asthma.

3.5. Real-Time PCR Detection of Respiratory Viruses. According to the validated real-time PCR results, persisting A and 
TABLE 1: Clinical characteristics of different patient groups.

\begin{tabular}{|c|c|c|c|c|c|c|c|c|c|c|c|c|}
\hline \multirow{2}{*}{$\begin{array}{l}\text { Patient } \\
\text { groups } \\
(n=59)\end{array}$} & \multirow[t]{2}{*}{ Age (years) } & \multirow[t]{2}{*}{$\begin{array}{l}\text { Male-female } \\
\text { ratio }\end{array}$} & \multirow[t]{2}{*}{$\mathrm{AOM}^{1} /$ year } & \multirow[t]{2}{*}{$\mathrm{AS}^{2} /$ year } & \multirow[t]{2}{*}{ OSAS $^{3}$} & \multicolumn{2}{|c|}{$\begin{array}{l}\text { Type of middle } \\
\text { ear effusion } \\
\text { (number of ears) }\end{array}$} & \multicolumn{3}{|c|}{$\begin{array}{l}\text { Preoperative } \\
\text { tympanometry } \\
\text { (number of ears) }\end{array}$} & \multirow[t]{2}{*}{$\begin{array}{l}\text { Bronchial } \\
\text { asthma }\end{array}$} & \multirow[t]{2}{*}{$\begin{array}{l}\text { Allergic } \\
\text { rhinitis }\end{array}$} \\
\hline & & & & & & Serous & Mucous & A & B & C & & \\
\hline $\begin{array}{l}\text { RAOM }^{6} \\
(n=25)\end{array}$ & $\begin{array}{c}5.12 \\
(3-11)\end{array}$ & $\begin{array}{c}16 / 9 \\
(1.77)\end{array}$ & $\begin{array}{c}6.72 \\
(2-14)\end{array}$ & $\begin{array}{c}5.41 \\
(2-9)\end{array}$ & $\begin{array}{c}2 \\
(8 \%)\end{array}$ & $\begin{array}{c}0 \\
(0 \%)\end{array}$ & $\begin{array}{c}0 \\
(0 \%)\end{array}$ & $\begin{array}{c}31 \\
(62 \%)\end{array}$ & $\begin{array}{c}0 \\
(0 \%)\end{array}$ & $\begin{array}{c}19 \\
(38 \%)\end{array}$ & $\begin{array}{c}0 \\
(0 \%)\end{array}$ & $\begin{array}{c}1 \\
(4 \%)\end{array}$ \\
\hline $\begin{array}{l}\mathrm{OME}^{7} \\
(n=19)\end{array}$ & $\begin{array}{l}4.63 \\
(3-8)\end{array}$ & $\begin{array}{l}12 / 7 \\
(1.71)\end{array}$ & $\begin{array}{c}1.21 \\
(0-4)\end{array}$ & $\begin{array}{c}1.31 \\
(0-3)\end{array}$ & $\begin{array}{c}17 \\
(89 \%)\end{array}$ & $\begin{array}{c}18 \\
(47 \%)\end{array}$ & $\begin{array}{c}14 \\
(37 \%)\end{array}$ & $\begin{array}{c}5 \\
(13 \%)\end{array}$ & $\begin{array}{c}32 \\
(84 \%)\end{array}$ & $\begin{array}{c}1 \\
(3 \%)\end{array}$ & $\begin{array}{c}4 \\
(21 \%)\end{array}$ & $\begin{array}{c}9 \\
(47 \%)\end{array}$ \\
\hline $\begin{array}{l}\text { OSAS }^{8} \\
(n=15) \\
\end{array}$ & $\begin{array}{c}4.93 \\
(3-11) \\
\end{array}$ & $\begin{array}{c}9 / 6 \\
(1.5) \\
\end{array}$ & $\begin{array}{l}0.33 \\
(0-1) \\
\end{array}$ & $\begin{array}{c}0.4 \\
(0-1) \\
\end{array}$ & $\begin{array}{c}15 \\
(100 \%) \\
\end{array}$ & $\begin{array}{c}0 \\
(0 \%) \\
\end{array}$ & $\begin{array}{c}0 \\
(0 \%) \\
\end{array}$ & $\begin{array}{c}27 \\
(90 \%) \\
\end{array}$ & $\begin{array}{c}0 \\
(0 \%) \\
\end{array}$ & $\begin{array}{c}3 \\
(10 \%) \\
\end{array}$ & $\begin{array}{c}2 \\
(13 \%) \\
\end{array}$ & $\begin{array}{c}4 \\
(27 \%) \\
\end{array}$ \\
\hline
\end{tabular}

${ }^{1}$ Acute suppurative otitis media. ${ }^{2}$ Acute sinusitis. ${ }^{3}$ Obstructive sleep apnea syndrome. ${ }^{4}$ Due to visual evaluation during intraoperative tympanocentesis and suction. ${ }^{5} \mathrm{~A}$ : normal curve; B: flat curve due to middle ear fluid. C: deviated curve due to negative middle ear pressure. All tympanometric measurements were performed the day before adenoidectomy. ${ }^{6}$ Recurring acute otitis media group. ${ }^{7}$ Otitis media with effusion group. ${ }^{8}$ Obstructive sleep apnea syndrome group.

B types of influenza virus (Iv-A and B) could not be detected in the adenoid specimens (Tables 2 and 3). The detectability of RSV and hMPV did not achieve a significant level and could be established as an accidental association in different patient groups (Tables $2-4$ ). In contrast, RSV and hMPV were exclusively detected in the OME group. The mainly associated viral pathogens were originated from various serotypes of $\mathrm{RV} / \mathrm{EV}$, AdV, and HBoV species (Tables 2-4). Table 2 presents the individual coexpression patterns of different respiratory viruses. All virus-negative cases $(n=7)$ belonged to the RAOM group, while patients of OME and OSAS groups were all characterized by various coexpressions of respiratory viruses (Tables 3 and 4). The RAOM group was exclusively associated with the presence of RV/EV AdV species (Tables 3 and 4 ). In the OSAS group, HBoV was detected in $54 \%$ of cases, which was mainly coexpressed with RV/EV (20\%) and AdV serotypes (27\%) (Table 4, Figure 1). Only one case was characterized by individual persistence of $\mathrm{HBoV}$ (Table 4). All specimens of the OME group were characterized by HBoV (Tables 3 and 4, Figure 1). Furthermore, eight of nine cases with individual expression of $\mathrm{HBoV}$ belonged to the OME group (Table 4). It was found that individual presence $(P<0.001$, Chi-square test $)$ or codetection $(P<0.05$, Chi-square test) of $\mathrm{HBoV}$ in the adenoid tissue is a strong predictor of OME associated with adenoid hypertrophy (Tables 3 and 4, Figure 1).

3.6. Histopathologic Examination. Histopathologic analysis revealed inflammatory adenoid tissues with lymphocytic, plasmacytic, or eosinophilic and polymorphonuclear infiltration of the subepithelial stroma in all cases. Bacterial biofilms were detected in 21 (35.59\%) of 59 patients with adenoid hypertrophy (Table 3, Figure 2). In the biofilm-negative cases $(n=38,64.41 \%)$, histopathologic analysis revealed a regular respiratory mucosa with predominantly lymphocytic infiltration of the subepithelial layer (Table 3, Figure 3). Overall, the great majority (>95\%) of biofilm-positive cases were originated from the RAOM group, where the prevalence of bacterial biofilms was $80 \%$ (Table 3 ). In contrast, biofilms could not be detected in the OME group. In the OSAS group, bacterial biofilms represented $6 \%$ of prevalence (Table 3 ). Independently from the associated symptoms, all patients diagnosed with allergic rhinitis were recruited into the biofilm-negative group (Table 3 ). The presence of bacterial biofilms was strongly associated to the histopathologic characteristics of epipharyngeal mucosa and also to the dominant inflammatory cell type of the subepithelial layer (Chi-square test; Table 3, Figures 2 and 3). Biofilm-negative cases were characterized by normal respiratory mucosa with columnar ciliated epithelium and goblet cells (Table 3, Figure 2). Disintegration or cellular metaplasia of the respiratory mucosa was strongly associated to the presence of biofilms (Chi-squaretest; Table 3, Figure 2). It was found that polymorphonuclear or plasmacytic infiltrations and disintegrated architecture of the subepithelial (stromal) layer are the most important predictors of biofilm presence (Table 3, Figure 3). In contrast, predominant lymphocytic infiltration and the presence of several centrum germinativum significantly decreased the chance of biofilm detection (Chi-square-test; Table 3, Figure 3).

\section{Discussion}

In the present study, we demonstrated the presence of bacterial biofilms in 21 patients with adenoid hypertrophy by the combined application of H.E. and Gram staining. Individual presence or coinfections of respiratory viruses were detected in 52 adenoid specimens. Results were correlated to the integrity of respiratory mucosa and also to the microscopic architecture of the subepithelial layer. It was found that the presence of bacterial biofilms or persisting respiratory viruses, mainly $\mathrm{HBoV}$, is a strong predictor of RAOM and OME, respectively. RAOM cases were significantly associated with biofilm existence, epithelial destruction, and stromal disintegration. Furthermore, all virus-negative cases belonged to this group of patients. In contrast, OME cases were characterized by biofilm negativity and normal architecture of the respiratory mucosa and the subepithelial layer. Beyond that all OME cases were positive for $\mathrm{HBoV}$; all individual expressions of this virus were recruited in this patient group. It should be established that the presence of $\mathrm{HBoV}$ displayed a statistically significant correlation to OME cases associated with adenoid hypertrophy. The main limitation of our study is the relatively low number of subjects, which should be increased in the future in order to obtain more precise statistical correlations. Nevertheless, we could not 
TABLE 2: Individual pattern of respiratory virus specific real-time (RT) PCR.

\begin{tabular}{|c|c|c|c|c|c|c|c|c|}
\hline \multirow{2}{*}{ Patient number } & \multicolumn{8}{|c|}{ Virus-specific real-time PCR } \\
\hline & Infl $A^{1}$ & Infl $B^{2}$ & $\mathrm{RSV}^{3}$ & $\mathrm{hMPV}^{4}$ & $\mathrm{RV} / \mathrm{EV}^{5}$ & $\mathrm{AV}^{6}$ & $\mathrm{hBoV}^{7}$ & $\mathrm{CC}^{8}$ \\
\hline 1 & - & - & - & - & + & + & - & + \\
\hline 2 & - & - & - & - & + & + & + & + \\
\hline 3 & - & - & - & - & + & - & - & + \\
\hline 4 & - & - & - & - & + & - & - & + \\
\hline 5 & - & - & - & - & + & + & - & + \\
\hline 6 & - & - & - & - & - & + & + & + \\
\hline 7 & - & - & - & - & + & - & - & + \\
\hline 8 & - & - & - & - & - & - & - & + \\
\hline 9 & - & - & - & - & + & + & - & + \\
\hline 10 & - & - & - & - & + & + & - & + \\
\hline 11 & - & - & - & - & - & + & - & + \\
\hline 12 & - & - & - & - & - & + & - & + \\
\hline 13 & - & - & - & - & + & - & - & + \\
\hline 14 & - & - & - & - & + & + & - & + \\
\hline 15 & - & - & - & - & - & - & + & + \\
\hline 16 & - & - & - & - & - & + & + & + \\
\hline 17 & - & - & - & - & - & + & + & + \\
\hline 18 & - & - & - & - & - & + & - & + \\
\hline 19 & - & - & - & - & + & + & + & + \\
\hline 20 & - & - & - & - & + & + & - & + \\
\hline 21 & - & - & - & - & - & - & + & + \\
\hline 22 & - & - & - & - & + & - & + & + \\
\hline 23 & - & - & - & - & - & - & + & + \\
\hline 24 & - & - & - & - & + & + & - & + \\
\hline 25 & - & - & - & - & + & - & + & + \\
\hline 26 & - & - & - & + & - & - & + & + \\
\hline 27 & - & - & - & - & + & - & - & + \\
\hline 28 & - & - & - & - & - & - & - & + \\
\hline 29 & - & - & - & - & + & - & + & + \\
\hline 30 & - & - & - & - & + & + & + & + \\
\hline 31 & - & - & - & - & - & - & + & + \\
\hline 32 & - & - & - & - & - & - & + & + \\
\hline 33 & - & - & - & - & - & + & - & + \\
\hline 34 & - & - & - & - & - & + & - & + \\
\hline 35 & - & - & - & - & + & + & - & + \\
\hline 36 & - & - & - & - & - & - & + & + \\
\hline 37 & - & - & - & - & - & + & - & + \\
\hline 38 & - & - & - & - & - & + & + & + \\
\hline 39 & - & - & - & - & - & + & - & + \\
\hline 40 & - & - & - & - & - & - & - & + \\
\hline 41 & - & - & - & - & - & + & - & + \\
\hline 42 & - & - & - & - & - & + & + & + \\
\hline 43 & - & - & - & - & - & - & - & + \\
\hline 44 & - & - & - & - & - & - & + & + \\
\hline 45 & - & - & - & - & - & + & - & + \\
\hline 46 & - & - & - & - & - & - & + & + \\
\hline 47 & - & - & + & - & + & - & + & + \\
\hline 48 & - & - & - & - & - & - & - & + \\
\hline 49 & - & - & - & - & - & - & - & + \\
\hline 50 & - & - & - & - & + & + & + & + \\
\hline
\end{tabular}


TABLE 2: Continued.

\begin{tabular}{|c|c|c|c|c|c|c|c|c|}
\hline \multirow{2}{*}{ Patient number } & \multicolumn{8}{|c|}{ Virus-specific real-time PCR } \\
\hline & $\operatorname{Infl} A^{1}$ & $\operatorname{Infl} \mathrm{B}^{2}$ & $\mathrm{RSV}^{3}$ & $\mathrm{hMPV}^{4}$ & $\mathrm{RV} / \mathrm{EV}^{5}$ & $\mathrm{AV}^{6}$ & $\mathrm{hBoV}^{7}$ & $\mathrm{CC}^{8}$ \\
\hline 51 & - & - & - & - & - & - & - & + \\
\hline 52 & - & - & - & - & - & - & + & + \\
\hline 53 & - & - & - & - & - & + & - & + \\
\hline 54 & - & - & - & - & + & + & + & + \\
\hline 55 & - & - & - & - & + & + & - & + \\
\hline 56 & - & - & - & - & - & - & + & + \\
\hline 57 & - & - & - & + & - & - & + & + \\
\hline 58 & - & - & - & - & - & - & + & + \\
\hline 59 & - & - & - & - & + & + & + & + \\
\hline
\end{tabular}

${ }^{1}$ Influenza-A virus, ${ }^{2}$ influenza-B virus, ${ }^{3}$ respiratory syncytial virus, ${ }^{4}$ human metapneumovirus, ${ }^{5}$ rhinovirus and enterovirus, ${ }^{6}$ adenovirus, ${ }^{7}$ human bocavirus, and ${ }^{8}$ cellular control.

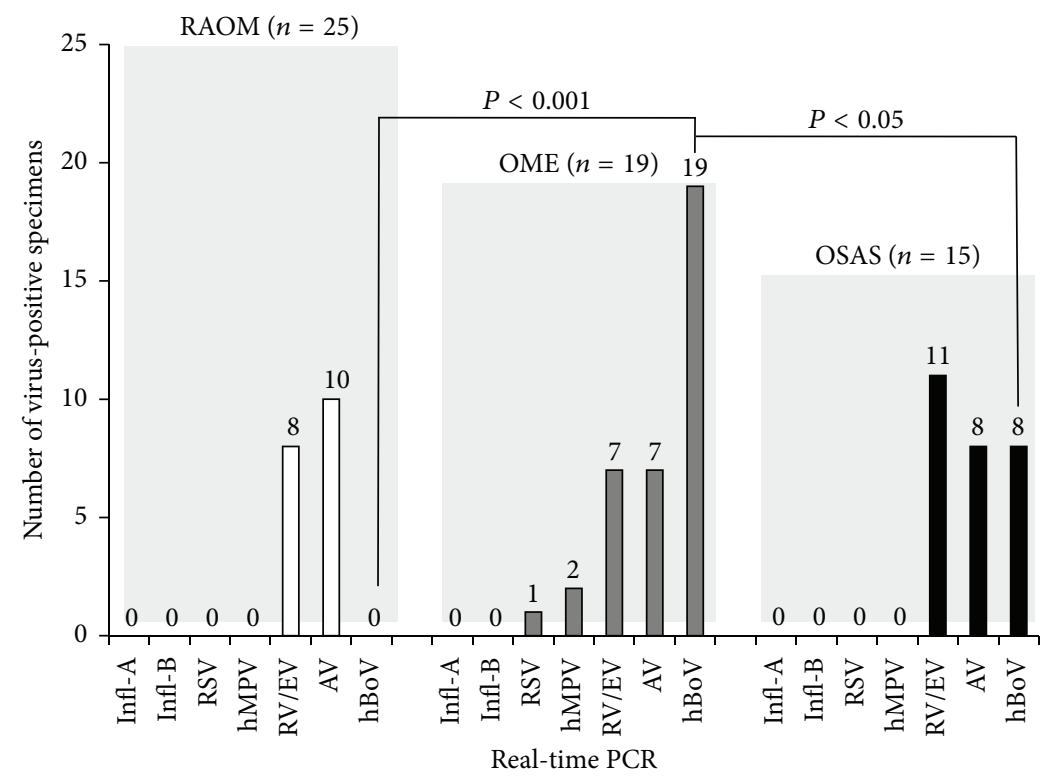

FIGURE 1: Graphic representation of respiratory virus specific real-time PCR results in different patient groups. RAOM: recurring acute otitis media; OME: otitis media with effusion; OSAS: obstructive sleep apnea syndrome.

exclude the seasonal pattern of respiratory virus infections in our patients. Furthermore, biofilm detection was based on the combined applications of H.E. and Gram staining protocols that were not correlated to the widely accepted methods of biofilm detection such as FISH (fluorescent in situ hybridization), CLSM (confocal laser scanning microscopy), and SEM (scanning electron microscopy) [25]. We did not intend to make a precise identification of bacterial species, because the presence of biofilm itself is thought to be the most important factor in the pathogenesis of OME and RAOM cases [3, 9-11].

The mechanical hypothesis emphasizes the importance of nasopharyngeal obstruction caused by adenoid hypertrophy $[1,7]$. This theory can explain only a limited fraction of symptoms associated with adenoid hypertrophy, such as nasal obstruction, hyponasality, olfactory dysfunction, snoring, mouth breathing, and disturbed facial and teeth development $[1,5,12,13]$. It has been reported that physical disproportion between the volume of adenoid and epipharyngeal space is the most important factor in the pathogenesis of OSAS [4, $5,12]$. Beyond the serious pathophysiological consequences, OSAS may cause various behavioral problems, such as anxiety, depression and attention deficits, or hyperactivity $[4,5]$.

The reservoir hypothesis emphasizes the direct or indirect role of persisting respiratory pathogens in the pathogenesis of RAOM and OME associated with adenoid hypertrophy $[9,15,17,21]$. The main bacterial pathogens in RAOM cases are the Streptococcus pneumoniae, Moraxella catarrhalis, and Haemophilus influenzae $[22-24,26]$. Both streptococci and Haemophilus species are potent biofilm-forming pathogens that may result in chronic persistence in the adenoid lacunae $[21,23,26]$. Acute exacerbations of otitis media may originate from this bacterial reservoir due to ascending reinfections via the Eustachian tube $[1,9,17]$. These bacteria can usually be cultured from the purulent effusion obtained from the middle ear $[24,26]$. 


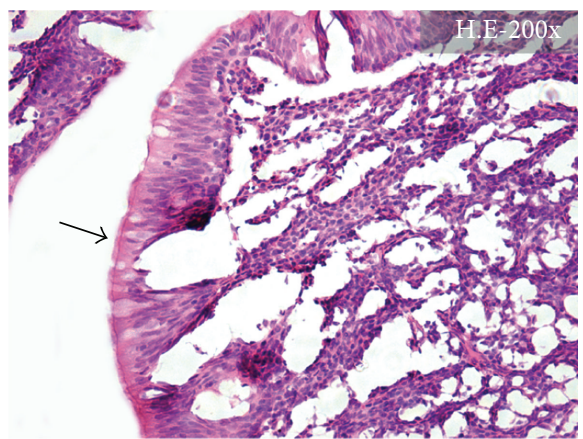

(A1)

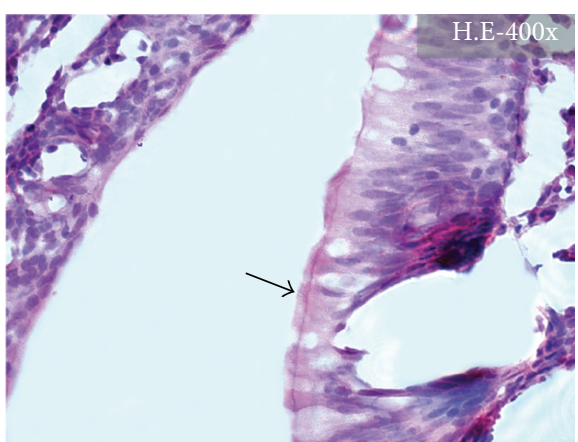

(A2)

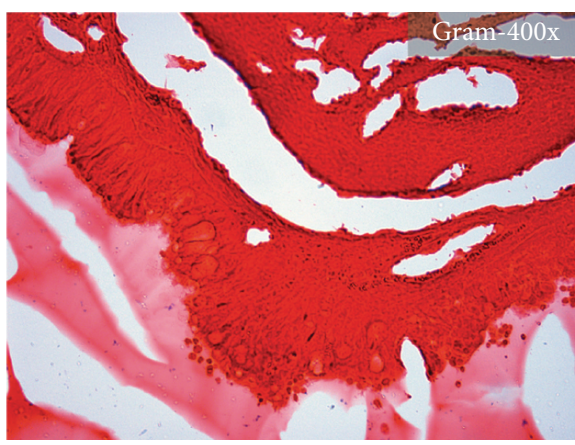

(A3)

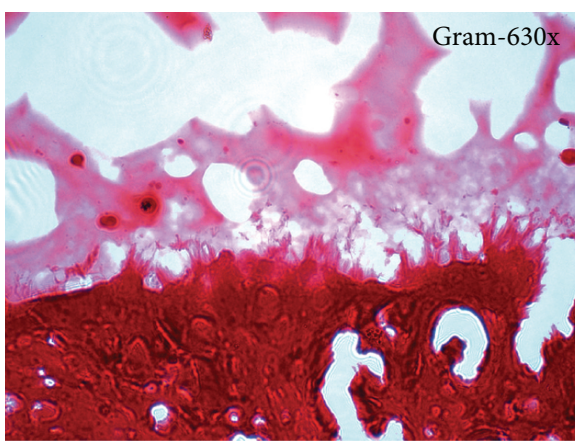

(A4)

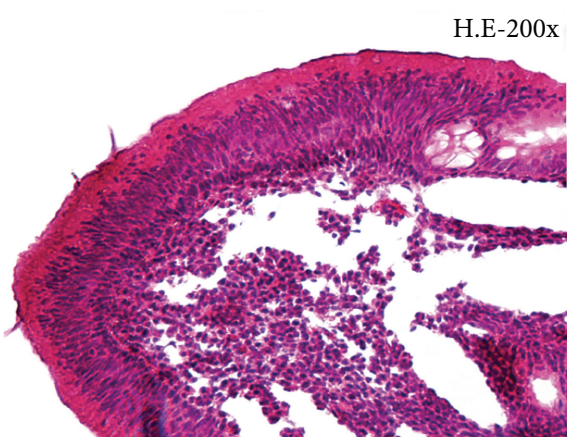

(B1)

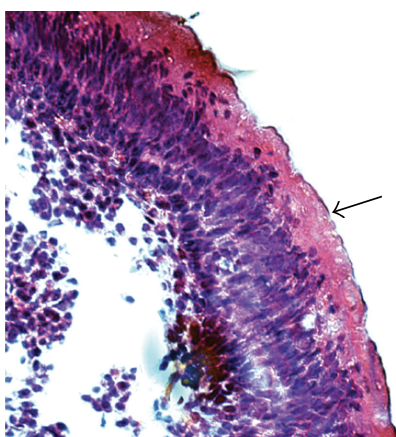

(B2)

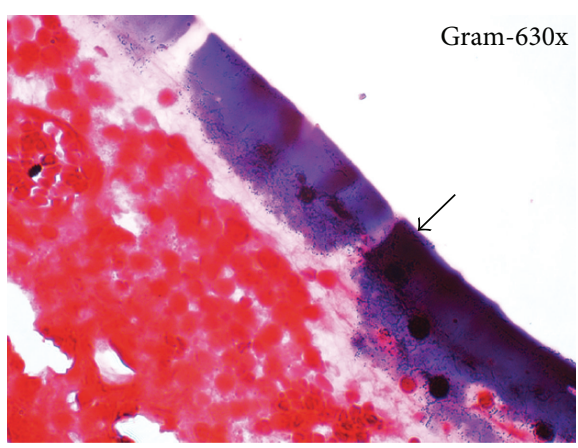

(B3)

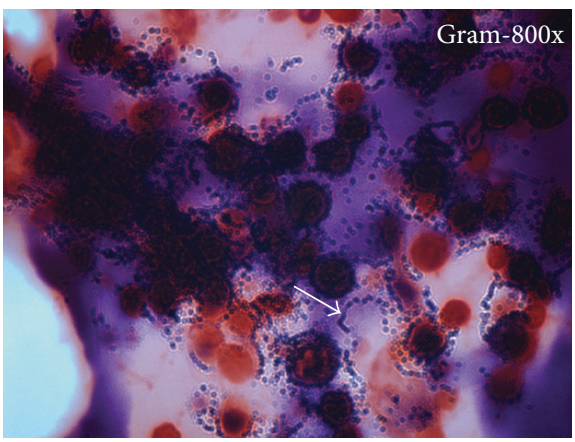

(B4)

FIGURE 2: Histopathologic representation of the respiratory epithelium in adenoid specimens of patients from OME and RAOM groups. (A1) At low magnification, regular columnar epithelium can be detected (black arrow, H.E.). (A2) Higher magnification view of the previous section. Black arrow indicates intact ciliated cells. (A3) Biofilm structures cannot be detected on the surface of epipharyngeal epithelium (Gram). (A4) Higher magnification view of the previous section. (B1) The epithelial layer is disintegrated and covered by a thick eosinophilic structure (black arrow, H.E.). (B2) At higher magnification, biofilm layer is a well identifiable structure (black arrow). (B3) Gram staining reveals a bacterial biofilm consisted of individual colonies of Gram-positive cocci (black arrow). (B4) Higher magnification view of the previous section. White arrow indicates Gram-positive cocci in a chain-pattern of streptococci. 


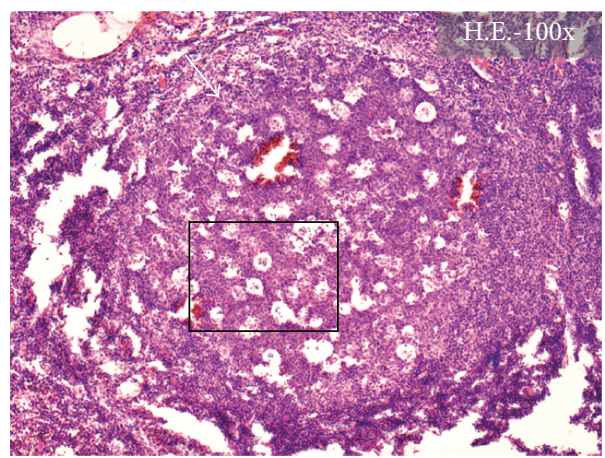

(A1)

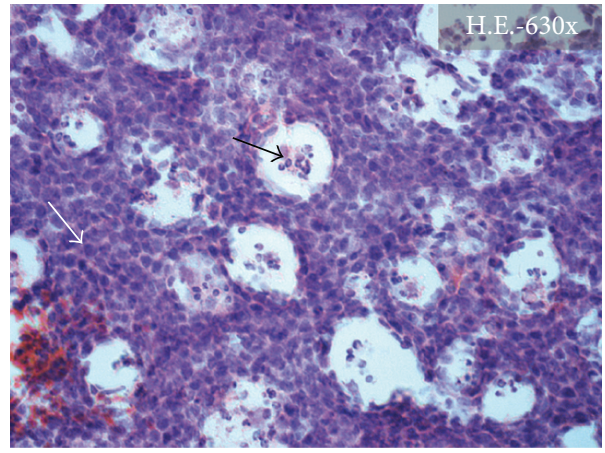

(A2)
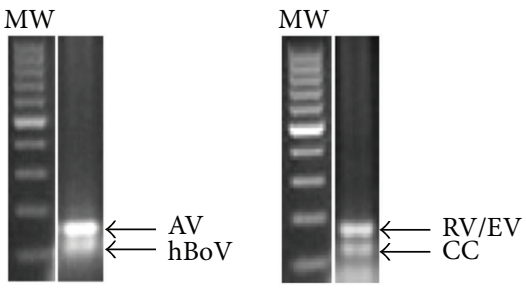

(A3)

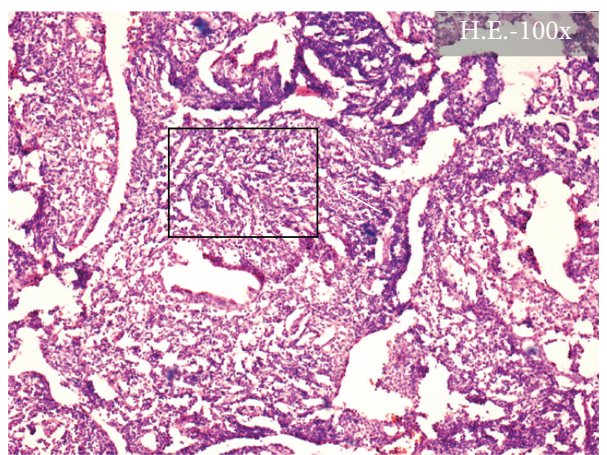

(B1)

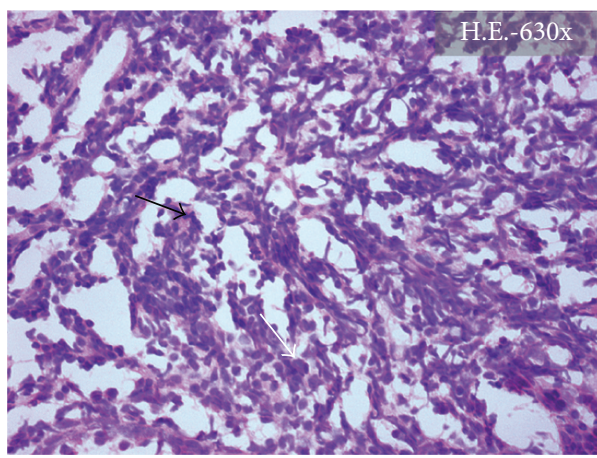

(B2)
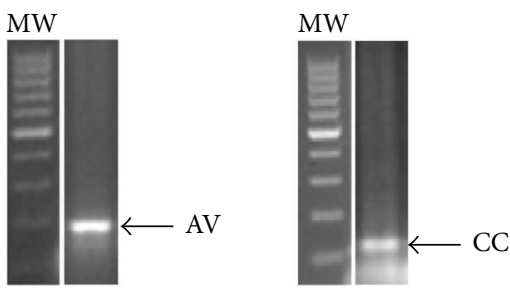

(B3)

FIGURE 3: Histopathologic representation of the stromal substance in adenoid specimens of patients from the OME and RAOM groups. (A1) Normal centrum germinativum (white arrow, H.E.). (A2) Higher magnification of the previous section. White arrow indicates large lymphocytes, while immunoblasts and centroblasts are shown by black arrow. (A3) Agarose gel electrophoresis of real-time PCR products of the identical specimen. Positive reactions were shown for Adenovirus (AdV), Human Bocavirus (hBoV), and for Rhinovirus-Enterovirus (RV/EV) serotypes. CC: cellular control. (B1) Disintegrated stromal substance without centrum germinativums (white arrow, H.E.). (B2) At higher magnification view, several polymorphonuclear cells (black arrow) and plasmocytes (white arrow) can be identified. (B3) Agarose gel electrophoresis of real-time PCR products of the identical specimen. The sample showed individual expression of Adenovirus (AV). CC: cellular control.

In contrast, $\mathrm{OME}$ is a chronic disease that is characterized by conductive hearing loss, persisting type-B tympanograms, special otoscopic findings, painless aural fullness, and by mental problems in some cases $[3,6,10,11]$. The serous or mucous effusions obtained during tympanocentesis or ventilation tube insertion are often negative for bacteria according to the results of conventional microbiological analysis [3, $9,15,16]$. At this time, OME is suspected to be a complex immunologic disorder of the middle ear cleft, which is mediated by the interactions of persisting respiratory viruses and impaired immune responses $[15,16]$. It has been reported that RV/EV species, HBoV, RSV, and AdV might play an important role in the pathogenesis of OME [18, 27-30].
Suggesting the importance of B-cell mediated immunoreaction, Rezes et al. have reported increased albumin-globulin ratio $(>0.7)$ in the middle ear fluids obtained from patients with OME [20]. Recent studies have demonstrated increased expression of IL-4, IL-11, and IFN-gamma and decreased levels of IL-1, TNF-alpha, or TGF-beta in the serous or mucous middle ear effusions suggesting the role of humoral immune response in the pathogenesis of OME [14-16, 20].

According to our results, distinct clinical pictures of adenoid hypertrophy can be characterized by different histopathologic and virus expression profiles. Adenoidectomy with or without tympanocentesis or ventilation tube insertion still remains the gold standard for the treatment of 
TABLE 3: Summary of respiratory virus specific real-time (RT) PCR results and histologic findings in different patient groups.

\begin{tabular}{|c|c|c|c|}
\hline & \multicolumn{3}{|c|}{ Patient groups $(n=59)$} \\
\hline & $\begin{array}{l}\text { RAOM group } \\
\quad(n=25)\end{array}$ & $\begin{array}{l}\text { OME group } \\
(n=19)\end{array}$ & $\begin{array}{l}\text { OSAS group } \\
(n=15)\end{array}$ \\
\hline \multicolumn{4}{|l|}{ Real-time PCR } \\
\hline Infl A & 0 & 0 & 0 \\
\hline Infl B & 0 & 0 & 0 \\
\hline RSV & 0 & 1 & 0 \\
\hline hMPV & 0 & 2 & 0 \\
\hline $\mathrm{RV} / \mathrm{EV}$ & 8 & 7 & 11 \\
\hline AV & 10 & 7 & 8 \\
\hline hBoV & 0 & 19 & 8 \\
\hline Cellular control & 25 & 19 & 15 \\
\hline Biofilm positivity & 20 & 0 & 1 \\
\hline \multicolumn{4}{|l|}{ Mucosa } \\
\hline $\begin{array}{l}\text { Normal respiratory } \\
\text { mucosa }\end{array}$ & 5 & 19 & 15 \\
\hline $\begin{array}{l}\text { Mucosal } \\
\text { disintegration } \\
\text { and/or metaplasia }\end{array}$ & 20 & 0 & 0 \\
\hline \multicolumn{4}{|l|}{ Stroma } \\
\hline $\begin{array}{l}\text { Normal structure } \\
\text { with centrum } \\
\text { germinativum }\end{array}$ & 8 & 19 & 15 \\
\hline $\begin{array}{l}\text { Neutrophil and/or } \\
\text { eosinophil } \\
\text { granulocyte } \\
\text { infiltration }\end{array}$ & 17 & 0 & 0 \\
\hline
\end{tabular}

TABLE 4: Respiratory virus coexpression pattern in different patient groups.

\begin{tabular}{lccc}
\hline $\begin{array}{l}\text { Virus } \\
\text { co-expression } \\
\text { pattern }\end{array}$ & $\begin{array}{c}\text { Patient groups }(n=59) \\
(n=25)\end{array}$ & $\begin{array}{c}\text { OME group } \\
(n=19)\end{array}$ & $\begin{array}{c}\text { OSAS group } \\
(n=15)\end{array}$ \\
\hline $\begin{array}{l}\text { Undetectable } \\
\mathrm{RV} / \mathrm{EV}\end{array}$ & $3(28 \%)$ & 0 & 0 \\
$\mathrm{RV} / \mathrm{EV}+\mathrm{AV}$ & $5(20 \%)$ & 0 & $3(20 \%)$ \\
$\mathrm{RV} / \mathrm{EV}+\mathrm{hBoV}$ & 0 & $1(5 \%)$ & $4(27 \%)$ \\
$\mathrm{RV} / \mathrm{EV}+\mathrm{AV}+$ & 0 & $5(26 \%)$ & $1(7 \%)$ \\
$\mathrm{hBoV}$ & 0 & $1(5 \%)$ & 0 \\
$\mathrm{RV} / \mathrm{EV}+\mathrm{RSV}+$ & $10(40 \%)$ & 0 & 0 \\
$\mathrm{hBoV}$ & 0 & $8(42 \%)$ & $1(7 \%)$ \\
$\mathrm{AV}$ & 0 & $2(10 \%)$ & $3(20 \%)$ \\
$\mathrm{hBoV}$ & 0 & $2(10 \%)$ & 0 \\
$\mathrm{AV}+\mathrm{hBoV}$ & & & \\
$\mathrm{hMPV}+\mathrm{hBoV}$ & & & \\
\hline
\end{tabular}

adenoid hypertrophy; however, further research may introduce targeted therapies in the future. In conclusion, adenoid hypertrophy-associated conditions are diseases of multifactorial agents involving disturbed local immune response and chronic inflammation. Furthermore, persisting respiratory viruses and bacterial biofilms might contribute to the damage of respiratory epithelium and subsequent hyperplasia of the subepithelial layer leading to functional disorder of the Eustachian tube and impaired immunoreactivity of the middle ear cleft.

\section{Ethical Approval}

This study was approved by the Institutional Ethical Committee.

\section{Consent}

This study was carried out according to the declaration of Helsinki. All subjects gave their informed written consent to our study.

\section{Disclosure}

The authors declare that this paper is an original work and it has not been published nor submitted to another journal. There are no prior publications or submissions with any overlapping information, including studies and patients. The authors state that the paper has not been and will not be submitted to any other journal.

\section{Conflict of Interests}

The authors state that they have no conflict of interests.

\section{Authors' Contribution}

All authors have read and accepted the final version of the paper. All authors contributed equally to this work.

\section{Acknowledgments}

This work was supported by the Grants of Hungarian Scientific Research Fund (OTKA PD75371 and OTKA K81480) and Research Fund of European Union (TÁMOP 4.2.1.B).

\section{References}

[1] G. L. Marseglia, D. Caimmi, F. Pagella et al., "Adenoids during childhood: the facts," International Journal of Immunopathology and Pharmacology, vol. 24, no. 4, pp. 1-5, 2011.

[2] J. M. Bernstein, "Waldeyer's ring and otitis media: the nasopharyngeal tonsil and otitis media," International Journal of Pediatric Otorhinolaryngology, vol. 49, no. 1, pp. 127-132, 1999.

[3] M. Cunningham, E. Guardiani, H. J. Kim, and I. Brook, "Otitis media," Future Microbiology, vol. 7, pp. 733-753, 2012.

[4] A. D. Goldbart and A. Tal, "Inflammation and sleep disordered breathing in children: a state-of-the-art review," Pediatric Pulmonology, vol. 43, no. 12, pp. 1151-1160, 2008.

[5] R. Arens and C. L. Marcus, "Pathophysiology of upper airway obstruction: a developmental perspective," Sleep, vol. 27, no. 5, pp. 997-1019, 2004.

[6] G. A. Zielhuis, G. H. Rach, and P. van den Broek, "The occurrence of otitis media with effusion in Dutch pre-school 
children," Clinical Otolaryngology and Allied Sciences, vol. 15, no. 2, pp. 147-153, 1990.

[7] M. B. Ugur, S. M. Dogan, A. Sogut et al., "Effect of adenoidectomy and/or tonsillectomy on cardiac functions in children with obstructive sleep apnea," Otorhinolaryngology and Its Related Specialties, vol. 70, no. 3, pp. 202-208, 2008.

[8] J. L. Paradise, C. D. Bluestone, K. D. Rogers et al., "Efficacy of adenoidectomy for recurrent otitis media in children previously treated with tympanostomy-tube placement. Results of parallel randomized and nonrandomized trials," Journal of the American Medical Association, vol. 263, no. 15, pp. 2066-2073, 1990.

[9] G. Saylam, E. Ç. Tatar, I. Tatar, A. Özdek, and H. Korkmaz, "Association of adenoid surface biofilm formation and chronic otitis media with effusion," Archives of Otolaryngology, vol. 136, no. 6, pp. 550-555, 2010.

[10] K. Daly, G. S. Giebink, C. T. Le et al., "Determining risk for chronic otitis media with effusion," Pediatric Infectious Disease Journal, vol. 7, no. 7, pp. 471-475, 1988.

[11] P. S. Roland, T. Finitzo, S. Friel-Patti et al., "Otitis media. Incidence, duration, and hearing status," Archives of Otolaryngology, vol. 115, no. 9, pp. 1049-1053, 1989.

[12] M. Greenfeld, R. Tauman, A. DeRowe, and Y. Sivan, "Obstructive sleep apnea syndrome due to adenotonsillar hypertrophy in infants," International Journal of Pediatric Otorhinolaryngology, vol. 67, no. 10, pp. 1055-1060, 2003.

[13] M. Alkhalil and R. Lockey, "Pediatric obstructive sleep apnea syndrome (OSAS) for the allergist: update on the assessment and management," Annals of Allergy, Asthma and Immunology, vol. 107, no. 2, pp. 104-109, 2011.

[14] L. Hafrén, E. Kentala, T. M. Järvinen et al., "Genetic background and the risk of otitis media," International Journal of Pediatric Otorhinolaryngology, vol. 76, no. 1, pp. 41-44, 2012.

[15] P. Cassano and M. Cassano, "Otitis media and immunological alterations of Waldeyer's ring," Advances in Oto-RhinoLaryngology, vol. 72, pp. 164-169, 2011.

[16] J. M. Bernstein, "Immunologic reactivity in the middle ear in otitis media with effusion," Otolaryngologic Clinics of North America, vol. 24, no. 4, pp. 845-858, 1991.

[17] L. Nistico, R. Kreft, A. Gieseke et al., "Adenoid reservoir for pathogenic biofilm bacteria," Journal of Clinical Microbiology, vol. 49, no. 4, pp. 1411-1420, 2011.

[18] J. L. Proenca-Modena, F. C. P. Valera, M. G. Jacob et al., "High rates of detection of respiratory viruses in tonsillar tissues from children with chronic adenotonsillar disease," PLoS ONE, vol. 7, Article ID e42136, 2012.

[19] L. Drago, S. Esposito, E. De Vecchi et al., "Detection of respiratory viruses and atypical bacteria in children's tonsils and adenoids," Journal of Clinical Microbiology, vol. 46, no. 1, pp. 369-370, 2008.

[20] S. Rezes, K. Késmárki, S. Sipka, and I. Sziklai, “Characterization of otitis media with effusion based on the ratio of albumin and immunoglobulin G concentrations in the effusion," Otology and Neurotology, vol. 28, no. 5, pp. 663-667, 2007.

[21] E. Macassey and P. Dawes, "Biofilms and their role in otorhinolaryngological disease," Journal of Laryngology and Otology, vol. 122, no. 12, pp. 1273-1278, 2008.

[22] K. A. Al-Mazrou and A. S. Al-Khattaf, "Adherent biofilms in adenotonsillar diseases in children," Archives of Otolaryngology, vol. 134, no. 1, pp. 20-23, 2008.

[23] R. E. Kania, G. E. M. Lamers, M. J. Vonk et al., "Characterization of mucosal biofilms on human adenoid tissues," Laryngoscope, vol. 118, no. 1, pp. 128-134, 2008.
[24] J. Coticchia, G. Zuliani, C. Coleman et al., "Biofilm surface area in the pediatric nasopharynx: chronic rhinosinusitis vs obstructive sleep apnea," Archives of Otolaryngology, vol. 133, no. 2, pp. 110-114, 2007.

[25] L. Tóth, P. Csomor, I. Sziklai, and T. Karosi, "Biofilm detection in chronic rhinosinusitis by combined application of hematoxylin-eosin and gram staining," European Archives of Oto-Rhino-Laryngology, vol. 268, no. 10, pp. 1455-1462, 2011.

[26] E. L. Tonnaer, G. T. Rijkers, J. F. Meis et al., "Genetic relatedness between pneumococcal populations originating from the nasopharynx, adenoid, and tympanic cavity of children with otitis media," Journal of Clinical Microbiology, vol. 43, no. 7, pp. 3140-3144, 2005.

[27] S. Rezes, M. Söderlund-Venermo, M. Roivainen et al., "Human bocavirus and rhino-enteroviruses in childhood otitis media with effusion," Journal of Clinical Virology, vol. 46, no. 3, pp. 234-237, 2009.

[28] N. Clément, G. Battaglioli, R. L. Jensen et al., "Prevalence of human bocavirus in human tonsils and adenoids," Emerging Infectious Diseases, vol. 15, no. 7, pp. 1149-1150, 2009.

[29] C. T. Garnett, G. Talekar, J. A. Mahr et al., "Latent species C adenoviruses in human tonsil tissues," Journal of Virology, vol. 83, no. 6, pp. 2417-2428, 2009.

[30] N. Soh, D. Nadal, J. M. Bernstein, E. Schlapfer, and P. L. Ogra, "Immunologic response of adenoidal lymphocytes to respiratory syncytial virus," Annals of Otology, Rhinology and Laryngology, vol. 101, no. 10 I, pp. 848-853, 1992. 


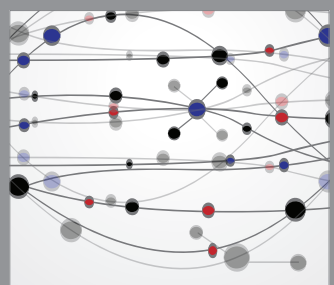

The Scientific World Journal
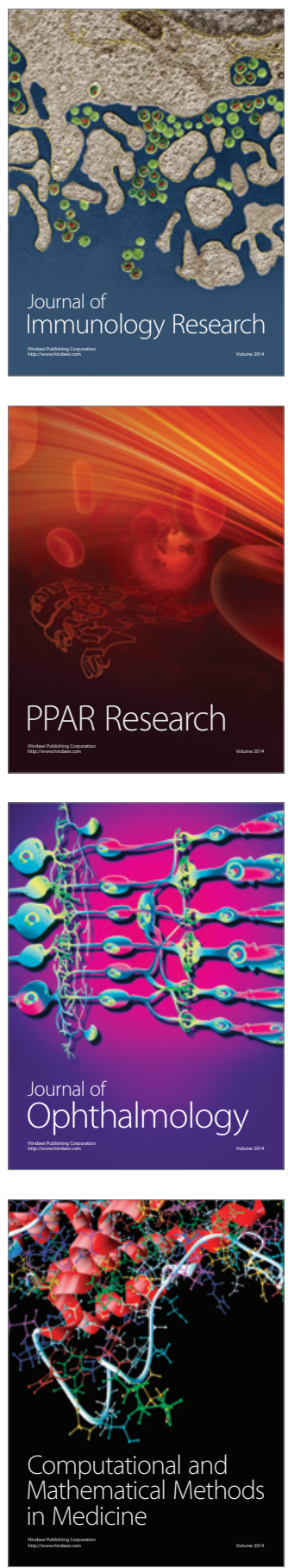

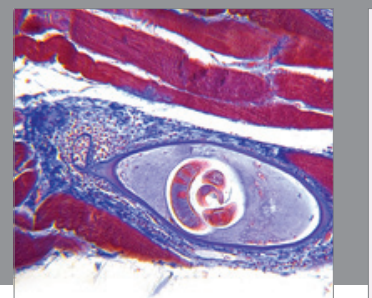

Gastroenterology

Research and Practice
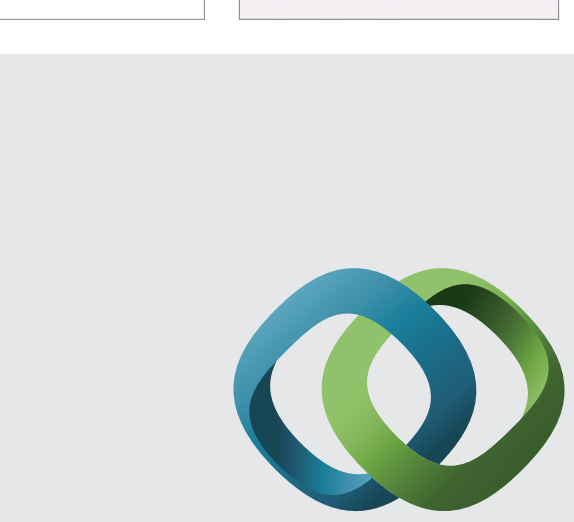

\section{Hindawi}

Submit your manuscripts at

http://www.hindawi.com
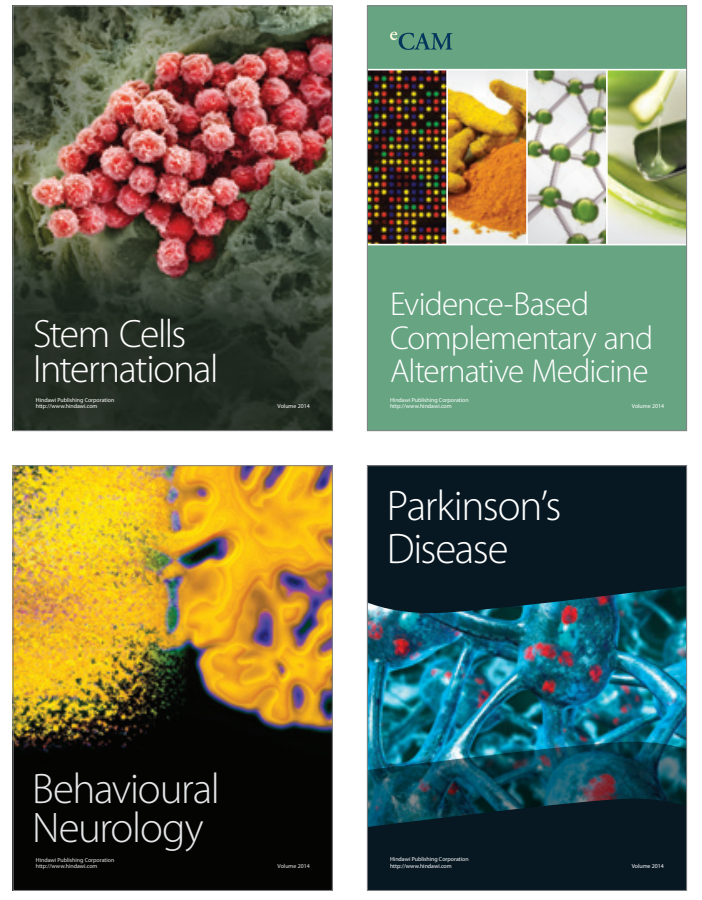
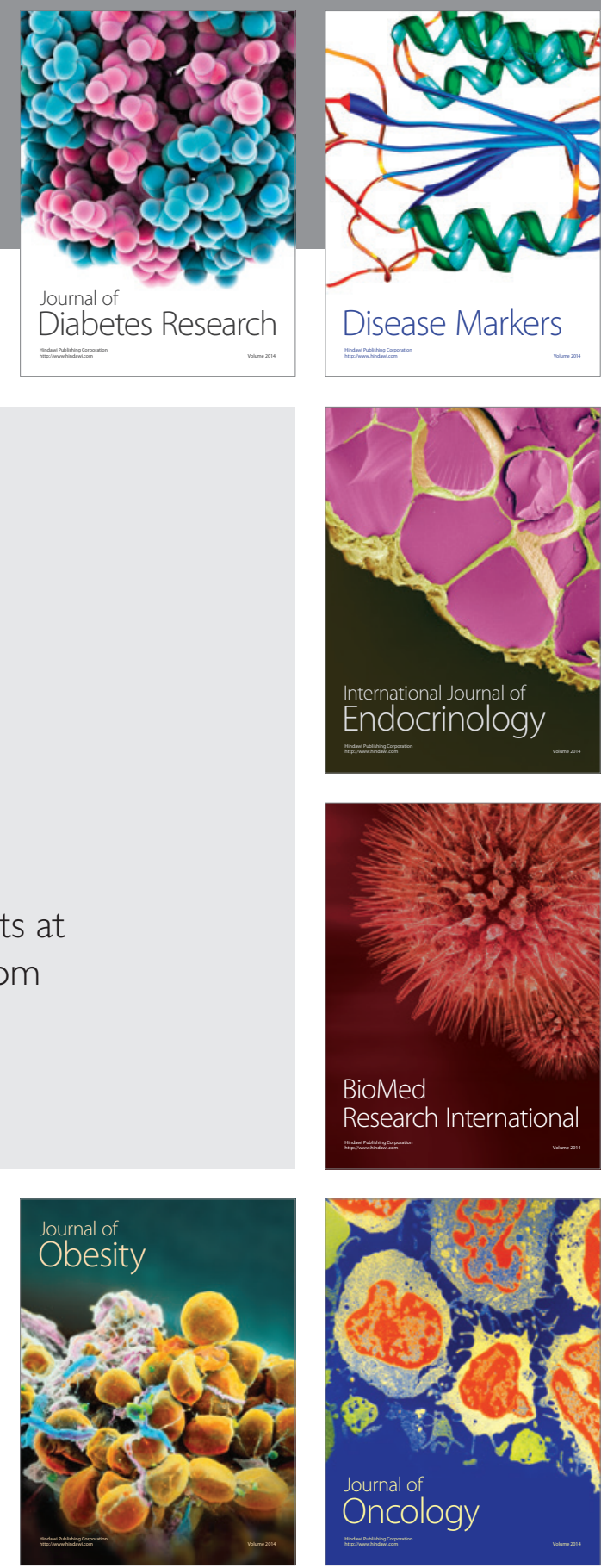

Disease Markers
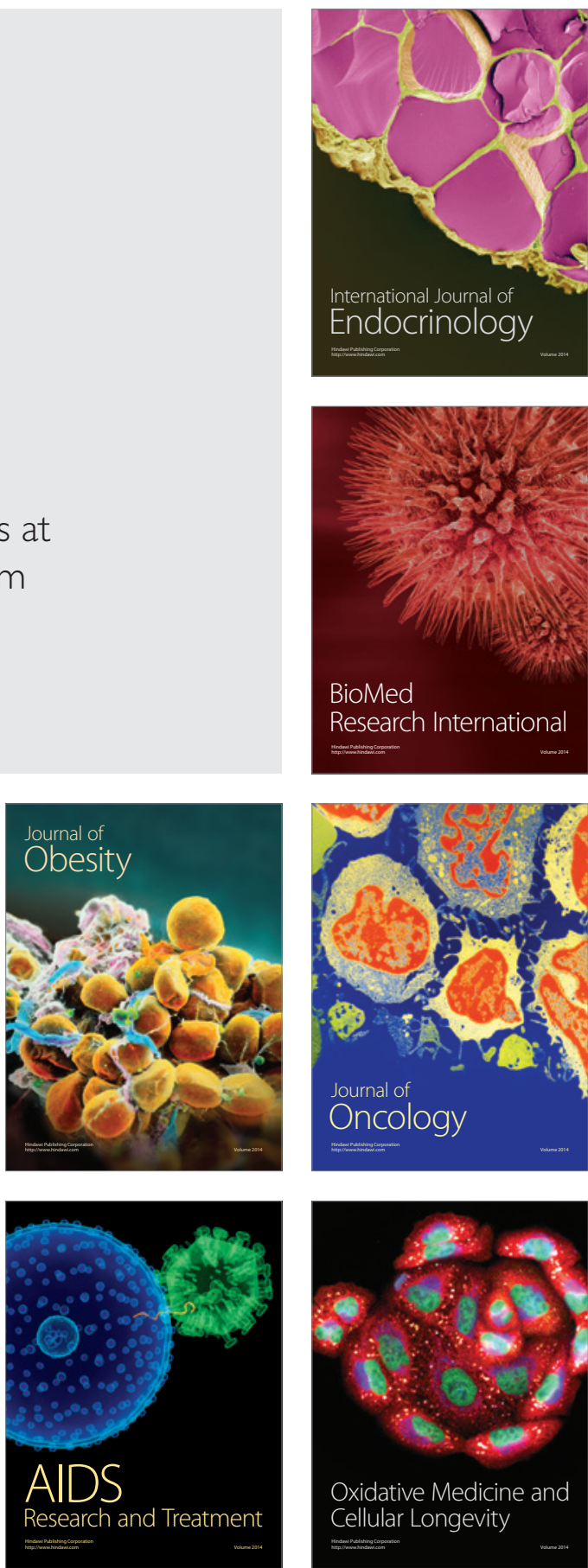